\title{
Aetiology of hyperthyroidism in Canada and Wales
}

\author{
IAN WILLIAMS, ${ }^{1}$ VIVIENNE O ANKRETT, ${ }^{1}$ JOHN H LAZARUS, ${ }^{1}$ AND ROBERT \\ VOLPE ${ }^{2}$
}

From the Department of Medicine, ${ }^{1}$ Welsh National School of Medicine, University Hospital of Wales, Cardiff, Wales, and the Department of Medicine, ${ }^{2}$ Wellesley Hospital, Toronto, Ontario, Canada

SUMMARY A retrospective, comparative review of 100 consecutive new outpatients presenting with hyperthyroidism in Cardiff, South Wales, and in Toronto, Canada, was performed. The aim was to quantify the causes of hyperthyroidism with particular emphasis on the prevalence of viral thyroiditis and "silent" thyroiditis. The proportional morbidity of Graves' disease (approximately $70 \%$ ) was similar in the two groups. Toxic multinodular goitre and toxic adenoma (Plummers' disease) occurred significantly more frequently in Cardiff $(25 \% v 8 \%)$, whereas thyroiditis predominated in Toronto $(17 \% \vee 1 \%)$.

The main causes of hyperthyroidism are Graves' disease, toxic multinodular goitre, and toxic adenoma. ${ }^{1}$ Although there are many other causes, these are rare. ${ }^{2}$ Nevertheless, hyperthyroidism due to subacute (de Quervain's) thyroiditis (SAT) ${ }^{3}$ together with so-called "silent" thyroiditis ${ }^{4}$ is now being increasingly recognised.

The prevalence of hyperthyroidism due to subacute thyroiditis is difficult to ascertain but several epidemics have been described in the North American continent. ${ }^{5-7}$ One outbreak has been described in Finland. ${ }^{8}$ As many of the reports of subacute thyroiditis and thyroiditis related hyperthyroidism have come from the North American continent ${ }^{4-11}$ it has been thought that the contribution of thyroiditis to cases of hyperthyroidism was greater in that area than in the United Kingdom.

The aim of the present study was, therefore, to determine the proportional morbidity of the different causes of hyperthyroidism in two study groups in Cardiff, Wales, and Toronto, Canada.

\section{Patients and methods}

One hundred consecutive patients were studied retrospectively from each centre. They were examined at the Wellesley Hospital, Toronto (Professor R Volpe), and at the thyroid clinic (University Hospital of Wales); they had presented to these clinics over the same period of the year. For the study, each patient's records at both centres were examined by I W and V O A during the tenure of a final year student elective project under the guidance of $J \mathbf{H ~ L}$ and $R \mathrm{~V}$ respectively. The diagnosis at review was reached in the light of the reported clinical assessment, biochemical data, antibody studies, radioiodine uptake and scans, together with histology when available.

Graves' hyperthyroidism was diagnosed by the clinical symptoms and signs (particularly those affecting the eyes) of hyperthyroidism associated with raised serum $T_{4}$ and $T_{3}$ concentrations, a diffuse thyroid uptake on radioiodine scanning, together with either a raised radioiodine uptake or an absent TSH response to TRH $200 \mu \mathrm{g}$ intravenously, or both. Antithyroglobulin and antimicrosomal antibodies were measured on all patients and where possible thyrotrophin displacing antibodies were assayed.

Toxic multinodular goitre was diagnosed in patients with hyperthyroidism by scanning together with histological examination after surgery if performed. Toxic adenoma was similarly diagnosed. diagnosed.

The presenting features of subacute thyroiditis (de Quervain's thyroiditis) are fever, malaise, and dysphagia associated with an enlarged tender thyroid gland. In de Quervain's thyroiditis there is usually severe pain and exquisite tenderness in the regions of the gland associated with a raised erythrocyte sedimentation rate (not seen in silent thyroiditis). The diagnosis of thyroiditis related hyperthyroidism was confirmed by a very low or absent radioiodine or technetium uptake by the gland, though the value depends on what stage of the disease the scan is performed. It was considered essential to perform 
radioisotope uptakes in all patients to avoid making an erroneous diagnosis of Graves' disease. All patients with a low radioiodine uptake were carefully questioned about their iodine intake. Hashimoto's disease associated with hyperthyroidism was inferred by the presence of high titres of circulating antimicrosomal and antithyroglobulin antibodies.

Serum $T_{4}, T_{3}, T S H$, and thyroid antibodies (antithyroglobulin and antimicrosomal) were measured by routine methods. Thyrotrophin displacing antibodies were measured using a radio receptor assay. ${ }^{12}$

\section{Results}

The mean age of the Canadian patients ( 37 years SD 17 ; range 13-82) was significantly lower than that of the Cardiff group (48 SD 17; range 10-77) $(\mathrm{p}<0.0001)$. The female to male ratio was $6: 1$ in Canada and 11:1 in Wales.

Most patients, in both groups, were diagnosed as having Graves' disease (table). The Canadian patients in this group were younger than the Welsh ones (Canadian 34 SD $15 v 44$ SD 17). An immediate family history of thyroid disease was noted in $56.7 \%$ of Canadians with Graves' disease compared with $40 \cdot 8 \%$ from Cardiff. There was a higher prevalence of toxic multinodular goitre and toxic adenoma in the Cardiff group (table) but the mean ages of the Cardiff patients with these conditions did not differ from those in Toronto. In Toronto $11 \%$ of patients presented with subacute thyroiditis and $6 \%$ with silent thyroiditis - that is, a total of $17 \%$-compared with only one patient with thyroiditis related hyperthyroidism in Cardiff.

\section{Discussion}

As the selection of patients for the study was consecutive in both centres it is thought that the two groups are broadly comparable and that conclusions may be drawn from the results; both groups were assessed in thyroid clinics and they were drawn from a similar catchment area. It should be noted, however, that this was a retrospective study and that referral patterns may differ in the two countries. This raises the question as to whether the incidence of the different causes of hyperthyroidism observed in the clinics reflects that seen in the community. This study cannot answer that. The racial composition of each group was not significantly different. We have confirmed that hyperthyroidism is a disease predominantly affecting women. While there are some data on the incidence and proportion of Graves' hyperthyroidism in the population ${ }^{13-15}$ there is little information on its prevalence in different defined populations of patients with hyperthyroidism. The present study has shown that in hyperthyroid patients who are carefully assessed about $70 \%$ will have Graves' hyperthyroidism. In these patients a positive family history of thyroid disease is apparent in both groups.

The aetiology of hyperthyroidism in the remaining $30 \%$ who did not have Graves' disease differed between the two centres. It is not clear why there was such a difference in the proportion of thyroiditis related hyperthyroidism between Toronto and Cardiff. In addition to subacute (painful) thyroiditis, initially described by de Quervain, silent thyroiditis (painless) is well recognised. There is evidence for a viral aetiology in the painful type $e^{4}$ but this is lacking for the painless variety. The $11 \%$ proportion of subacute thyroiditis in the hyperthyroid group in Toronto compares with $10 \%$ reported by Hamburger ${ }^{16}$ and $12.5 \%$ by Woolner et al. ${ }^{16}{ }^{17}$ Silent thyroiditis has been reported in up to $15 \%$ of hyperthyroid patients. While there was a significant number of cases due to this disease in Toronto only

Aetiology of hyperthyroidism in Cardiff and Toronto

\begin{tabular}{|c|c|c|c|c|c|c|c|}
\hline & & \multicolumn{2}{|l|}{ Men } & \multicolumn{2}{|l|}{ Women } & \multicolumn{2}{|c|}{ Positive family history } \\
\hline & & Cardiff & Toronto & Cardiff & Toronto & Cardiff & Toronto \\
\hline \multirow[t]{2}{*}{ Graves' } & $<45$ & 1 & 7 & 35 & 50 & 19 & 36 \\
\hline & $\geqslant 45$ & 5 & 3 & 30 & 14 & 10 & 6 \\
\hline \multirow[t]{2}{*}{ TMNG } & $<45$ & $\mathbf{0}$ & 0 & 1 & 0 & 0 & 0 \\
\hline & $\geqslant 45$ & 0 & 0 & 14 & 5 & 6 & 1 \\
\hline \multirow[t]{2}{*}{ Toxic adenoma } & $<45$ & 0 & 0 & 1 & 0 & 0 & $\mathbf{0}$ \\
\hline & $\geqslant 45$ & 1 & 0 & 8 & 3 & 4 & 1 \\
\hline \multirow[t]{2}{*}{ SAT } & $<45$ & 1 & 1 & 0 & 5 & 0 & 1 \\
\hline & $\geqslant 45$ & 0 & 1 & 0 & 4 & 0 & 1 \\
\hline \multirow[t]{2}{*}{ Silent thyroiditis } & $<45$ & 0 & 0 & 0 & 4 & 0 & 2 \\
\hline & $\geqslant 45$ & 0 & 0 & 0 & 2 & 0 & 0 \\
\hline \multirow[t]{2}{*}{ Hashitoxicosis } & $<45$ & $\mathbf{0}$ & 0 & 1 & 1 & 1 & 1 \\
\hline & $\geqslant$ & 0 & 0 & 2 & 0 & 0 & 0 \\
\hline
\end{tabular}

TMNG = Toxic multinodular goitre.

SAT $=$ Subacute thyroiditis. 
one case of thyroiditis related hyperthyroidism was discovered in the Cardiff patients. Its apparent rarity in the United Kingdom, compared with the North American continent, may also reflect different attitudes to health between the two cities. The transient nature of the illness and its symptoms and signs may be attributed to a "flu-like" illness by those unfamiliar with the disease. We suspect that cases may be missed by the family practitioners in Wales and consequently not referred to the thyroid clinic. There are no known differences between North America and United Kingdom in the prevalence of viral illnesses likely to cause thyrioditis, although the epidemiology has not been extensively investigated. We have no evidence that Canadian patients present earlier to their physician with hyperthyroidism. Possibly, however, the general level of knowledge and awareness of thyroiditis related hyperthyroidism is higher in Canada because of the publicity and interest that was given to early reports of the condition.

Toxic multinodular goitre was a cause of hyperthyroidism in the older members of both study groups. The higher proportion of toxic multinodular goitre in the Cardiff patients may be related to the demonstrable iodine deficiency in the Welsh valleys associated with a high prevalence of goitre. ${ }^{18}$ In contrast, Toronto has iodised salt and water and the incidence of multinodular goitre is significantly less. $^{19}$

Clearly, the geographic pattern of iodine distribution is important in partly accounting for the prevalence of toxic multinodular goitre in the Welsh area. Nevertheless, the influence of the intrathyroidal iodine concentration ${ }^{20}$ on the expression of Graves' disease (an immunological disorder) ${ }^{21}$ should not be overlooked. The recent description of a specific HLA association with disseminated thyroid autonomy, ${ }^{22}$ a condition occurring only in markedly iodine deficient areas, ${ }^{23}$ emphasises this point.

Although this study did not specifically examine differences in the treatment of hyperthyroidism between the two centres it was of interest to note that surgery was performed on $2 \%$ of patients in Toronto compared with $28 \%$ of those in Cardiff. Whereas radioiodine treatment is not generally used under the age of 45 in the United Kingdom it was administered to many patients aged between 20 and 45 in Canada.

The study has shown significant differences between two thyroid centres in the proportional morbidity of thyroiditis related hyperthyroidism and toxic multinodular and uninodular goitre in consecutive hyperthyroid patients. Further work in this area is indicated in order to define environmental and individual patient related factors which might account for these differences.

We are grateful to Professor $\mathbf{R}$ Hall for advice and criticism. This study was undertaken during the student elective period spent in Toronto by I W and V O A. We thank the records clerks in Wellesley General Hospital and the University Hospital of Wales for their help.

\section{References}

${ }^{1}$ Werner SC. Hyperthyroidism. In: Werner SC, Ingbar SH, eds. The thyroid. 4th ed. New York: Harper and Row, 1978, 591-603.

${ }^{2}$ Hamilton CR, Maloof F. Unusual types of hyperthyroidism. Medicine 1973; 52: 195-215.

${ }^{3}$ Volpe R. Subacute (de Quervain's) thyroiditis. Clinics in Endocrinology and Metabolism 1979; 8: 81-95.

"Papapetrou PD, Jackson IMD. Thyrotoxicosis due to "silent" thyroiditis. Lancet 1975; i: 361-3.

${ }^{5}$ Westwater IO. Subacute thyroiditis. Californian Medicine 1952; 76: 66-8.

${ }^{8}$ Stanley S, Bergen JR. Acute nonsuppurative thyroiditis: a report of twelve cases and a review of literature. Arch Intern Med 1958; 102: 747-60.

${ }^{7}$ Swann NH. Acute thyroiditis: a clinical report in twelve cases within a four month period. Annals Intern Med 1962; 56: 68-71

${ }^{8}$ Lamberg BA, Hintze G, Jussila R, Berlin M. Subacute thyroiditis. Acta Endocrinologica 1962; 33: 457-72.

${ }^{9}$ Gluck FB, Nusyowitz ML, Plymate S. Chronic lymphocytic thyroiditis, thyrotoxicosis, and low radioactive iodine uptake: report of four cases. $N$ Engl J Med 1975; 293: 624-8.

${ }^{10}$ Woolf PD, Daly R. Thyrotoxicosis with painless thyroiditis. Am J Med 1976; 60: 73-9.

${ }^{11}$ Dorfman SG, Cooperman MT, Nelson AL, Depuy H, Peak RL, Young RL. Painless thyroiditis and transient hyperthyroidism without goitre. Ann Intern Med 1977; 86: $24-8$.

${ }^{12}$ Smith BR, Hall R. Thyroid stimulating immunoglobulins in Graves' disease. Lancet 1974; ii: 427-31.

${ }^{13}$ Furszyfer J, Kurland LT, McConahey WM, Elveback LR. Graves' disease in Olmsted County, Minnesota, 1935 through 1967. Mayo Clin Proc 1970; 45: 636-44.

${ }^{14}$ Tunbridge WMG, Evered DC, Hall R, et al. Spectrum of thyroid disease in community. (The Whickham Survey.) Clinical Endocrinology 1977; 7: 481-93.

${ }^{15}$ Baldwin DB, Rowett D. Incidence of thyroid disorders in Connecticut. JAMA 1978; 239: 742-4.

${ }^{16}$ Hamburger JL. Subacute thyroiditis: diagnostic difficulties and simple treatment. J Nucl Med 1974; 15: 81-9.

${ }^{17}$ Woolner LB, McConahey WM, Beahrs OH. Granulomatous thyroiditis (de Quervain's thyroiditis).J Clin Endocrinol Metab 1957; 17: 1202-21.

${ }^{18}$ Trotter WR, Cochrane AL, Benjamin IT, Miall WE, Exley D. A goitre survey in the Vale of Glamorgan. British Journal of Preventive and Social Medicine 1962; 16: 16-21.

${ }^{19}$ Rosen F, Ezrin C, Volpe R. Iodide metabolism in Ontario. Acta Endocrinologica 1967; 54: 604-8. 
${ }^{20}$ Ingbar SH. Autoregulation of the thyroid response to iodide excess and depletion. Mayo Clin Proc 1972; 47: 814-23B.

${ }^{21}$ Hall R, McGregor AM, McLachlan S, Lazarus JH, Rees Smith B. The treatment of hyperthyroidism. In: Tunbridge WMG, ed. Advanced medicine. Tunbridge Wells: Pitman, 1981: 32-6.

To the Editor

Effects of tap water lead, water hardness, alcohol, and cigarettes on blood lead concentrations

SIR-This recent contribution by S J Pocock et al (March 1983,1-7) clearly shows the role of tap water and personal habits in raised blood lead concentrations. The authors, however, conclude by stating that "because direct evidence of a comparable nature has not been shown for lead in petrol ... lead in water should be given priority ...." Petrol lead sales in Boston, Massachusetts, have been shown to correlate very well with blood lead concentrations. ${ }^{1}$ We suggest that reduction in lead exposure requires attention to both air and water.

Children's Hospital Medical Center,

MICHAEL RABINOWITZ Boston, Massachusetts 02115, USA
${ }^{22}$ Schleusener H, Schernthaner G, Mayr W, et al. HLA-DR3 and HLA-DR5 associated thyrotoxicosis -2 different types of toxic diffuse goiter. Proceedings of 11 th annual meeting of the European Thyroid Association, Pisa 1981. Annales d'Endocrinologie 1981; 42: 14A.

${ }^{23}$ Studer H, Hunziker HR, Ruchti C. Morphologic and functional substrate of thyrotoxicosis caused by nodular goiters. Am J Med 1978; 65: 227-34.

\section{References}

${ }^{1}$ Rabinowitz M, Needleman HL. Petrol lead sales and umbilical cord blood lead levels in Boston, Massachusetts. Lancet 1983; i: 63.

Note: This letter was shown to the authors of the article who do not wish to reply but they would agree with the last sentence of the letter. Editor. 